\title{
De la vida y el espíritu: la dignidad del individuo
}

\author{
JAVIER GÁLVEZ AGUIRRE \\ Universidad de Granada
}

\section{Planteamiento general}

Quizá hemos de poner mucho de nuestra parte, imaginación incluida, si quisiéramos afirmar que el saber absoluto en la reflexión de una civilización sobre sí misma, esto es, en su propia eticidad (lo cual parece incluso poco apropiado) se puede dar efectivamente. Ese saber absoluto, mirada del filósofo que atiende al proceso histórico-lógico y lo comprende, ese para nosotros presente en todo el recorrido de la Fenomenología, ha de verse más bien como la indagación sobre el espíritu y la religiosidad mismas. Lo cierto es que todos nosotros, esto es, toda la civilización occidental, en definitiva, tiene muy presente aunque quizá de una manera no muy clara su concepto de dignidad $Y$ tal dignidad parece entenderse de modo general como la capacidad receptiva de derechos por parte del individuo. Esa dignidad, por tanto, puede entenderse ligada al valor de la individualidad, al que llamaremos, no sin ciertas reticencias, sagrado. Pues si en algo ha de diferir la dignidad de un individuo respecto cualquier ser natural, esto deberá entenderse precisamente como una cuestión de oposición de la dignidad y libertad humana a algo diferente a ella misma, y este algo es precisamente la vida. La idea principal que aquí pretendo mostrar es que si, precisamente la dignidad del individuo surge en parte por oposición a la vida, tal concepto de dignidad como sujetos receptores de derecho sin más parece mostrarse como insuficiente. Sólo parece hablarse de dignidad cuando el daño ya ha sido cometido o lo tenemos a la vista. Se nos olvida, en tal caso, que la dignidad como correlato de la libertad y como esencia de lo humano tiene también un carácter violento, aunque fuese mínimamente en una transformación del mundo. Y tal mundo se nos presenta como susceptible de ser transformado y como fuente de apetencia sobre el que ejercemos precisamente una fuerza que tiende a destruir parcialmente el movimiento de lo vivo en general. 


\section{LA AUTOCONCIENCIA ENSIMISMADA EN LA FENOMENOLOGÍA DEL ESPÍRITU}

Para entender mejor la cuestión de la dignidad del individuo, y poder hacerlo de un modo lo más sintético posible, sería conveniente entender cómo se configura la individualidad a lo largo de las fases de la conciencia que se van recorriendo en la Fenomenología. Los puntos álgidos de la misma, al menos para la temática que aquí tratamos, son los siguientes:

1. La individualidad como autoconciencia frente a la vida. El individuo, en tanto que repara sobre sí como autoconciencia, es la diferencia radical frente a la vida. Hasta tal punto que la vida misma no le puede dar aquél objeto máximamente querido por la misma autoconciencia. Una autoconciencia siempre busca otra autoconciencia, y éste paso, que cuesta entender en la primera lectura de este apartado de la Fenomenología se puede comprender precisamente por la radical diferencia entre autoconciencia y vida, pues, aunque la vida se articule como el momento de la necesidad y el destino descritos a lo largo de la misma obra, tal movimiento indiferenciado que es la vida misma no se atiene por completo al querer del individuo. La autoconciencia necesita, por tanto, completar la serie de los momentos independientes de la vida o, al menos, darles un orden según el baremo que la autoconciencia misma establezca de un modo reflexivo o no. Así el individuo, usando la misma expresión utilizada por Hegel precisamente en este tipo de pasajes, se entiende como momento discreto frente a la continuidad inmediata de la vida.

2. En el apartado siguiente de la Fenomenología, cuando la vida ha sido en parte subsumida y es la razón la que a ella se opone (o pretende investigar o sojuzgar), esta razón se descubre como el movimiento libre que hace de la ley el médium entre el movimiento de lo orgánico fluido y universal y la cosa misma de la naturaleza que pretende entender. Precisamente a causa de la necesidad que descubre en lo orgánico y su ley, a la par que en el conflicto entre la universalidad del movimiento y la particularidad del objeto subsumido, esta razón se comprende a sí misma en su libertad por su capacidad de sojuzgar lo natural mismo. Recuérdese que precisamente cuando la razón, en cuanto pretende comprenderse como autoconciencia, pone al individuo más bien como cosa y, viendo el desvarío o la incompletitud de tal aseveración, se ve empujada a comprenderse como espíritu. Aunque, eso sí, aún tal razón se encuentra más apegada a la singularidad de su autoconciencia que a la comunidad espiritual. Este descubrimiento de la libertad de la autoconciencia ya se podía entrever en la sección de fuerza y entendimiento de la Fenomenología: lo orgánico, la cosa, en definitiva, a estudiar nos 
hace recaer en el goce de sí de la conciencia, esto es, ya más bien de la autoconciencia, ya que ésta no es tanto un olvido de sí para la coseidad en general, como un atenderse a sí misma y a lo otro desde sí; es decir, teniéndose presente a sí en todo momento.

3 . En tercer lugar, la individualidad como tal vuelve a abrirse paso como enjuiciamiento moral o, visto aún desde el momento de la razón, como razón legisladora. La autoconciencia aquí se articula, en su libertad frente a la necesidad de la vida, como abstención de la mácula del movimiento de lo que se presenta a la par como contingente o lo que debería ser de otro modo. Si bien la autoconciencia ya ha ganado en sí el concepto de su libertad, se obstina en una libertad que, por no coincidir con la necesidad de la ley del mundo, con su curso característico, se mantiene en la abstención y en lo universal no realizado. Es, por tanto, una autoconciencia imposibilitada para la acción. Aquí sucede algo peculiar en relación con los momentos antes señalados: si la vida era precisamente aquello desde lo que se nos articula la libertad de la autoconciencia (y la libertad, precisamente, es el correlato de la dignidad, pero un correlato que habrá que aclararse), esta libertad universal que sabe tener cada individuo en su propio caso no quiere chocar con la vida misma, vida que, siendo universal y necesaria, no corresponde a ese tipo de necesidad de lo libre que ha ganado la autoconciencia como razón y como espíritu. La vida es lo universal que no corresponde al deber ser, sino a una ley extraña al goce del individuo que mira para sí o para los otros desde sí, por mor de un universal que no puede aplicar pues teme ser sojuzgado como meramente natural y no auténticamente espiritual.

Si algo hemos de sacar en claro de lo hasta ahora señalado con respecto a la individualidad, es precisamente que ésta, por comprenderse libre de un modo más o menos consciente, articula su acción según cómo entienda la cosa en general o la vida. $\mathrm{O}$, lo que es lo mismo, la vida se muestra no sólo como algo que podemos considerar inferior sin más según la posibilidad de valoración de la autoconciencia, sino que, de considerarla así, persiste sin embargo como momento que articula la propia espiritualidad del hombre por oposición a ésta. Los tres momentos señalados coinciden en que, en ellos, la vida en general es entendida como lo universal a transformar según el valor que la autoconciencia dé a su propia libertad. La vida presenta entonces esa doble faz de ser a la vez movimiento y disolución del mismo, es inmediatez en su conjunto y mediación en sus figuras que pretenden adquirir independencia:

"El elemento fluido es él mismo solamente la abstracción de la esencia; en otras palabras, sólo es real como figura; y al articularse en miembros desdobla, al mismo tiempo, lo articulado o lo disuelve. Todo este ciclo constituye la vida, $[\ldots]$ el 
todo que se desarrolla, disuelve su desarrollo y se mantiene simplemente en este movimiento" (G. W. F. Hegel, 2000, p. 111).

Ese trastorno de la vida misma en su fluidez es precisamente lo que el hombre pretende aprehender con el médium de la ley y que por ello puede llevarle a situaciones dispares que hemos venido señalando.

\section{III, LO VIVO Y LO MUERTO: LA POTENCIA DEL ENTENDIMIENTO}

Lo natural, por lo mismo, es la cosa en general que sigue siendo el polo opuesto de la conciencia incluso cuando se entiende como autoconciencia. Es, así, lo diferente del entendimiento mismo. Y querer ver el intelecto sin más como una facultad cognoscitiva sin más, imparcial y apta para comprender el mundo en sus leyes universales es un despropósito si tratamos de dar con la noción esencial del mismo en el sistema hegeliano. El entendimiento es precisamente la potencia infinita, la facultad no sólo teorética por sí misma, sino también volitiva (Cf. G. W. F. Hegel 2005, p. 511.), es esencialmente aquello que determina y lo determina para sí. Pues ya sabemos que para Hegel la distinción entre el terreno práctico y el teórico es simplemente una distinción formal que no da con la conciencia misma y que la escinde de un modo artificial, lo que conlleva a problemas más graves de los que se pretendían salvar. Frente a la vida como movimiento inmediato e indeterminado, el entendimiento le pone un freno al mundo y busca el objeto de su apetencia. Ponerle un freno significa, por lo pronto, establecerse como un movimiento que fija lo por sí mismo fluido. Sólo se puede querer aquello que articule el movimiento específico de la voluntad; la voluntad, instalada en una situación determinada, tiene al querer y al mundo como estructura universal, y al objeto del mundo y a la finalidad del entendimiento como particularidades que le posibilitan la acción. No hay acción universal sin más, sino que en ella se intuye, a través de lo particular, lo universal del mundo y la potencia total del entendimiento, dos modos de universalidad que se configuran como unidad en la consecución de la apetencia. Esta apetencia, como ya dijimos, no colma el goce que busca la autoconciencia. Pero sí que nos pone en camino de comprender que tal autoconciencia, para considerarse libre y espiritual, transforma lo diferente a ella en el obrar, rompe ese movimiento continuo de la vida y se planta como un momento discreto que actúa frente a la indeterminación inmediata del ser en general o la vida. Esta indeterminación de la vida, esta materia universal que es en realidad lo ideal sobre lo que la conciencia actúa, no puede quedarse, para un sujeto que se comprende desde su dignidad, como un paraíso en el que, según le conviene atendiendo a su naturaleza orgánica, lo recoge sin más; recolección que, por otra parte, vería como algo inocente o que no afecta a ese movimiento del mundo.

El entendimiento, desde luego, no es la facultad que permite la culminación de la dignidad del hombre. Es, antes que nada, esa facultad que, si bien 
violenta la realidad en general que en principio no es el entendimiento mismo, sí que consigue que nos percatemos de la diferencia que supone el hombre con respecto a la vida. Esa diferencia es una diferencia radical: el aquietar el movimiento y la misma separación del mismo nos coloca en un punto ontológico en el que lo orgánico es secundario, en el que la necesidad del mundo que comprendemos desde la observación nos hace recaer en que el individuo, dotado de entendimiento, es algo en parte diferente de aquello que aprehende. Esa diferencia es lo que llamamos libertad o espiritualidad, espiritualidad que es capaz de la muerte misma con tal de verse diferenciada con respecto a esa fluidez de la que no participa el hombre plenamente. El intelecto, antes de juzgar moralmente, retiene lo vivo y lo transforma, esto es, es capaz de introducir lo espiritual, que en cierto sentido es lo no vivo, o la muerte misma si se quiere, en esa indiferenciación total. De esa introducción parcial de la muerte proceden en parte los derechos del individuo.

\section{DEL SABER TEÓRICO AL SABER PRÁCTICO:}

LA DIGNIDAD PASIVA DEL SUJETO MORAL

Pero, por otra parte, hemos visto cómo el juicio moral, cómo el individuo seguro de esa su universalidad de la libertad o lo espiritual, no es capaz de acción, sino que se limita al enjuiciamiento de lo dado como malo o contingente. Tal conciencia moral siente el peligro de no ser comprendida en su espiritualidad, y por ello tacha a la vida según su inadecuación a lo moral mismo, y de ese choque entre la vida y el ser para sí del hombre moral nos queda que su acción no es tal, sino meramente intención. La acción, para la conciencia moral, que es precisamente la que establece la mayor diferencia con respecto a la vida, es fuente de problemas para mantenerse en su dignidad, pues en cuanto la conciencia digna o buena actúa, su universalidad como saber es colocada en lo universal indeterminado que es la vida, vida que es precisamente lo diferente de la libertad para tal autoconciencia. Llegados a este punto, la autoconciencia, si no quiere entenderse como libertad pasiva sin más, ha de efectuar un cambio radical, pues desde su propio ensimismamiento llega a contemplar dos mundos dentro de la propia autoconciencia, lo que puede ser bastante problemático:

"Pero en el hecho de que esto justo que hace la buena conciencia es al mismo tiempo ser para otro parece que se dé en ella una desigualdad. El deber que lo lleva a cabo es un determinado contenido, es evidentemente, el sí mismo de la conciencia y, en ello, su saber de sí, su igualdad consigo mismo. Pero, una vez llevada a cabo, colocada en el médium universal del ser, esta igualdad no es ya saber, no es ya esta diferenciación que supera también inmediatamente sus diferencias; sino que en el ser se pone como subsistente la diferencia y la acción determinada, desigual al elemento de la autoconciencia de todos $\mathrm{y}$, por tanto, no necesariamente reconocida"(G. W. F. Hegel, 2000, pp. 378-9). 
La disputa con la filosofía kantiana es aquí más que evidente, pero no podemos tratar de ella de un modo riguroso. La cuestión estriba en que la autoconciencia (que es conciencia para sí, pero autoconciencia para nosotros) como buena conciencia sigue enredada en un ensimismamiento que le impide obrar por miedo a que su acción caiga en el terreno de lo natural, su acción es la abstinencia o, a lo sumo, el enjuiciamiento moral que no se compromete con nada del mundo. La ganancia de la libertad en sí misma es en principio plena, pero tal libertad es precisamente poco más que ese correlato de dignidad que no pretende hacer daño a nadie y sin embargo busca lo contingente y lo vil del que sí que actúa realmente. El alma bella sufriente es incapaz de reconocer a las demás autoconciencias porque para ella misma la vida mancilla esa libertad. Y tal autoconciencia ha de comprender a los otros en comunidad y ha de introducirle, por tanto, un cierto sesgo de espiritualidad a la vida misma. Es aquí, precisamente, y como se puede entrever, donde entra la cuestión de la religiosidad.

\section{LA MORAL Y LO RELIGIOSO: LA ACCIÓN DE LO LIBRE}

Volvamos al tan desgastado pasaje en la historia de la filosofía del señor y el siervo. El punto que aquí nos interesa es precisamente que la muerte, como elemento que articula la autoconciencia para distinguirse de la vida, no puede ser el término medio de relación entre dos autoconciencias. Hasta ahora habíamos visto la cuestión de la dignidad de la autoconciencia desde una sola conciencia, la conciencia de cada uno. También hemos visto muy de pasada la impotencia del juicio moral y el alma bella, cuyo nosotros o comunidad queda diluído para resguardarse en su libertad interior que no puede ser profanada en la acción llevada a cabo en el elemento de la vida misma. El caso, como ya sabemos, es que la muerte de una de las dos autoconciencias no puede triunfar si se quiere avanzar en la dinámica de la autoconciencia: la muerte ha de ser siempre parcial, un as en la manga que es preferible no sacar a la luz. Pues si se lleva a cabo acaba con ese sustrato de lo espiritual que es precisamente la vida. El término medio, por tanto, no es la muerte, sino un elemento que aparece en la filosofía hegeliana de un modo un tanto sorprendente, y es precisamente la religiosidad. En efecto, la conciencia moral no puede poner fin a la discordia entre ella y el mundo, o entre ella y las demás conciencias (que siguen siendo para ella, en definitiva, mundo). El fin a la discordia se encontraba presente a la par que obviado por la propia conciencia, demasiado moral y demasiado intelectiva, desde que a la autoconciencia, en su lucha contra la vida o contra otras autoconciencias, se desgarraba dentro de sí y se comprendía como incompleta. Dos textos al respecto pueden aclarar la situación en la que nos encontramos:

"Su verdad [la de la conciencia desventurada] es aquello que en el silogismo, en el que los extremos [conciencia que es para sí negativa, y cuyo en sí es el más 
allá] aparecían absolutamente disociados, se manifestaba como el término medio que anuncia a la conciencia inmutable que lo singular ha renunciado a sí y a lo singular que lo inmutable no es ya un extremo para él, sino que se ha reconciliado con él"(G. W. F. Hegel, 2000, p. 143).

"El sí de la reconciliación, en el que los dos yo hacen dejación de su ser contrapuesto es el ser allí del yo extendido hasta la dualidad, que en ella permanece igual a sí mismo y tiene la certeza de sí mismo en su perfecta enajenación y en su perfecto contrario; -es el Dios que se manifiesta en medio de ellos, que se saben como el puro saber" (G. W. F. Hegel, 2000, p. 392).

Tanto el primer pasaje de la sección de Razón como el último de la sección de Espíritu aquí citados (teniendo en cuenta la diferente situación de la conciencia, pero remarcando también a su vez que en ambas situaciones el gesto de su situación es idéntico) nos dan la clave: es la religiosidad la que permite que el hombre obre en el mundo y que éste no le sea motivo de sospecha. Es la religiosidad la que reintroduce la vida en la conciencia y la que, no casualmente, era constantemente criticada por el espíritu ilustrado, espíritu que se atañe a la investigación del mundo y al uso de la vida para sí. Ese espíritu ilustrado mantiene con la moralidad una línea de continuidad en cuanto que considera la vida desde un para sí que, si bien a diferencia de la buena conciencia es moral, sigue determinando a la vida desde la potencia del entendimiento. $\mathrm{O}$ dicho de otro modo: la moral y la ilustración concuerdan en su diferenciación, consciente sólo en el primer caso, con respecto a la vida.

En definitiva, no hay una solución rápida a la cuestión de la dignidad del hombre. Aquí no se trata de hacer una llamada a la religiosidad sin más, pues no hay en el sistema hegeliano momentos que no tengan su parte de verdad. Lo que sí parece mostrarse como una problemática a tener en cuenta es si realmente nos encontramos en la disyuntiva de aceptar ese legado religioso que es el Cristianismo inopinadamente o si, más bien por el otro lado, seguimos manteniéndonos orgullosos de nuestra incansable capacidad de quejarnos de todos los problemas existentes y regodearnos en esa alma sensible que somos sin llegar a hacer nada al respecto. Lo cierto es que parece haber un hueco entre esas dos figuras que aún no hemos sido capaces de resolver, aunque sí que podemos ver históricamente una serie de términos medios fallidos que han entendido la inclusión de la muerte característica del sistema hegeliano precisamente al revés.

\section{REFERENCIAS}

HEGEL, G. W. F., 2000: Fenomenología del espíritu. México D. F.: FCE. , 2005 Enciclopedia de las ciencias filosóficas. Madrid: Alianza. 
